Session 10

\title{
Improve Learning Efficiency by Using Computers For Junior Level Electrical Engineering Courses
}

\author{
George G Karady, Fellow member IEEE \\ Arizona State University \\ Tempe AZ 85287 \\ Karady@asu.edu
}

\author{
K. A. Nigim*, Senior member IEEE \\ Birzeit University, Birzeit, Palestine \\ Knigim@imap3.asu.edu \\ *Fullbright Fellowship leave at Arizona State University
}

Keywords: Electric circuit, energy conversions, teaching, and computer application

\begin{abstract}
The paper presents a problem solving teaching method that uses personal computer based calculation software to introduce the practical use of engineering theories. The method permits students to study parameter and variables effects of an engineering case without writing complicated computer programs. The students enhance problem-solving abilities with the minimum requirements of programming skills as the course proceeds. The use of generalpurpose mathematical software GPMS as a teaching aid tool provides high flexibility for educators. Good handling of the built-in functions of GPMS minimizes the vigorous and labor systemic manual solution of equations. The paper presents the experience gained in conducting energy conversion course at ASU department of engineering with interactively integrating GPMS within the computer laboratory environment.
\end{abstract}

\section{INTRODUCTION}

Time and energy are saved once GPMS's are incorporated as an aid to teaching in the classroom. GPMS's are mathematical software capable of manipulating a general variety of mathematical equations and variables. The incorporation of GPMS into the classroom and in the laboratory experimentation enhances the interactivity between the student and the course material. This is one way to encourage the students to integrate with the course material that does not directly involve computerized tasks at early stages such as power and electrical machine courses. The lack of interactivity between the traditional course outline and modern tools resulted in a shift in the student enrollment in what could be classified as heavy current engineering courses. With the abundant availability of mathematical and engineering simulation 
software's, the task of re-shifting the student inclination is possible. Starting from the use of dedicated software incorporated in the textbook package [1] to navigated hyperlink data sites [2], the tutor can introduce the course material in such a way that personal student interaction is ensured.

GPMS provides high flexibility in comparison to the dedicated spreadsheet tools that necessitate the knowledge of code and the specific symbol [3]. Moreover, the use of general calculation software at the junior level allows for the numerical examples to support the theory and provide deeper understanding of the physical phenomena. Another advantage of using 'GPMS' is the development or enhancement of the problem solving ability of the student. Simultaneously the laborious and uninteresting numerical calculations using calculators is minimal. The students have to learn how to apply the equations and methods taught in the theory. This can be achieved by teaching the students to use the equations and calculation directly and perform the actual calculations by the software. In the recent years computer modeling and interactive problem solving are incorporated at many universities. Integrating the course material and the laboratory experimentation improved the student's interaction with minimum knowledge of programming skill [4,5].

The following sections introduce easy procedures with systematic problem solving techniques that enables the students to comprehend the phenomena and physical ties in the taught subject. The paper presents, by examples, a problem solving technique that can be easily followed by the students. The technique basically relies on the use of the built in functions incorporated in the GPMS. Starting from the theoretical information of the course material taught in its basic format i.e. Ohm's law, the student's can then investigate the different possibilities of the problem.

In the paper three examples are illustrated. The first example applies the problem solving procedures in evaluating the characteristics of a dc motor supplied by battery voltage source. The drawn motor current from the battery cause torque to be developed which is investigated as the motor speed is varied. The second example is a simple distribution network that includes a distribution transformer. The transformer efficiency and voltage regulation are investigated as the load varies. The third example investigates the stability of a transmission line before and after a load has been connected.

The advantages of the proposed method are:

1) The students write the equations in the familiar textbook format.

2) The problems are solved interactively, which increases student interest.

3) The students analyze the results and draw the conclusions, which enhance learning.

4) The general-purpose calculation programs are frequently used in industry.

5) There is no need to learn dedicated, input output type computer programs.

The paper does not make any comparison of the usage of available software; rather it focus on what has been used at ASU and proved to be successful. The examples demonstrate how the basic fundamental equations of the system can be developed into informative results using the built in functions of the used mathematical software.

"Proceedings of the 2001 American Society for Engineering Education Annual Conference \& Exposition Copyright C2001, American Society for Engineering Education" 
2. Transforming Theory to Mathematical Equations:

MathCad software was selected as a GPMS due to its flexibility and easy learning environment. A considerable amount of commercial software is available and is considered a necessary tool in today's engineering world. At the beginning of the semester, the student receives hand out showing the key features of the software and how MathCad main built-in features work with the course material. To assist the student in revising the course material, the text examples inputted in MathCad format are stored in an electronic handbook database and made available on the web page of the course. The use of the software is incorporated in every aspect of the course study and evaluation. Units and dimension of the constants and variables are included in the examples and are used as part of solution verification. The students calculate the equivalent elements of the system as a function of the variables from tests results. Then, using the Ohm law, the internal variables (current, power and losses) are determined as a function of the external variables (input voltage, frequency and load). The students learn how to observe and describe the physical case into electric equivalent circuit. Once the variables and possible operating range are identified, the problem can be investigated to its limit and the student will learn how to predict and interact with the problem. The use of the built in features minimizes the need for programming and software skills. The use of units and the selectable variable value permits the detection of errors, since MathCad will warn if the dimensions are not matched or the equation cannot be solved. After the derivation of the equations the students analyze the results by plotting the relevant parameters versus the variables.

The examples demonstrated in the following sections provide a straightforward technique in which the variables are estimated using the many build-in functions of the standard MathCad software.

\subsection{Application in understanding the electric motor characteristics}

The first example selected demonstrates the use of iteration routines (Given and Find) to evaluate the dc motor performance. Reference [6] introduces a comprehensive presentation of the induction machine equivalent circuit and the required experimentation procedures as part of integrating the student to the laboratory. Current and voltage supplied from the battery source and the generated back electromagnetic force ' $\mathrm{E}$ ' of the motor armature winding is written as a function of the variable motor speed. Each student calculates the motor resistive elements, current, speed, power and torque using the general calculation routines in line with the textbook procedures. The procedures used are displayed in the screen print out, shown in Figure. 1. The effect of the battery voltage dropping by $30 \%$ on the developed torque is plotted against the speed. The student will learn from the example that if a cubic law load was coupled to the motor the motor may fail to develop a useful torque once the battery voltage drops beyond $70 \%$ of its nominal level. The students interact with the problem and estimate the required energy needed by the battery to deliver the required load at the particular speed 'rpm' (prediction and interaction).

"Proceedings of the 2001 American Society for Engineering Education Annual Conference \& Exposition Copyright C2001, American Society for Engineering Education" 


\section{Example 1}

A dc shunt motor is supplied through a feeder with a battery. The motor drives a pump with the charactersitics follows a cubic law $\left(T(n)=a+b .(n)^{\wedge} 2\right)$.

Motor data are

$$
\mathrm{P}_{\text {rated }}:=5 \mathrm{hp} \quad \mathrm{V}_{\text {rated }}:=24 \mathrm{~V} \quad \mathrm{R}_{\mathrm{a}}:=0.1 \Omega \quad \mathrm{R}_{\mathrm{f}}:=10 \Omega
$$

Motor is tested and the test results are:

$$
\mathrm{V}_{\text {test }}:=\mathrm{V}_{\text {rated }} \quad \mathrm{I}_{\text {test }}:=90 \mathrm{~A} \quad \text { Let } ; \quad \mathrm{rpm}:=\min ^{-1} \quad \mathrm{n}_{\text {test }}:=850 \mathrm{rpm}
$$

Battery and feeder data are:

$$
\mathrm{V}_{\text {batt }}:=25 \mathrm{~V} \quad \mathrm{R}_{\text {batt }}:=0.1 \Omega \quad \mathrm{R}_{\text {feeder }}:=0.2 \Omega
$$

The pump torque vs speed characteristcs

$$
\mathrm{n}:=600 \mathrm{rpm}
$$

$\mathrm{a}:=1 \mathrm{~N} \cdot \mathrm{m}$

$$
\mathrm{b}:=0.002 \cdot \mathrm{N} \cdot \mathrm{m} \cdot \sec ^{2} \quad \mathrm{~T}_{\text {pump }}(\mathrm{n}):=\mathrm{a}+\mathrm{b} \cdot \mathrm{n}^{2}
$$

$\mathrm{P}_{\text {pump }}(\mathrm{n}):=\mathrm{T}_{\text {pump }}(\mathrm{n}) \cdot 2 \cdot \pi \cdot \mathrm{n}$

$$
\mathrm{P}_{\text {pump }}(\mathrm{n})=0.101 \mathrm{hp}
$$

Required answers for;

1) Draw the equivalent circuit and calculate motor parameters

2) Calculate the curents and voltages as a function of the speed

3) Plot the motor and pump torque vs. speed charcteristics

4) Determine to operation point, speed and torque

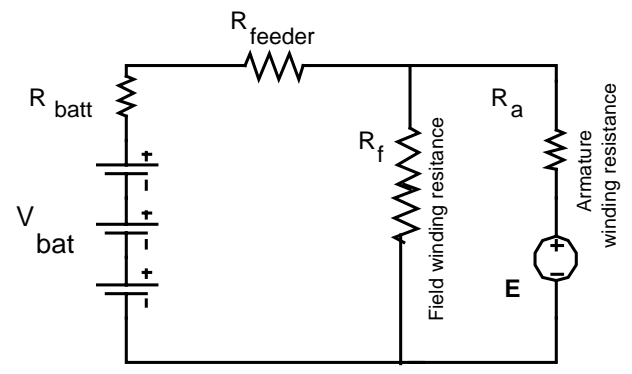

Battery operated DC motor equivalent circuit 


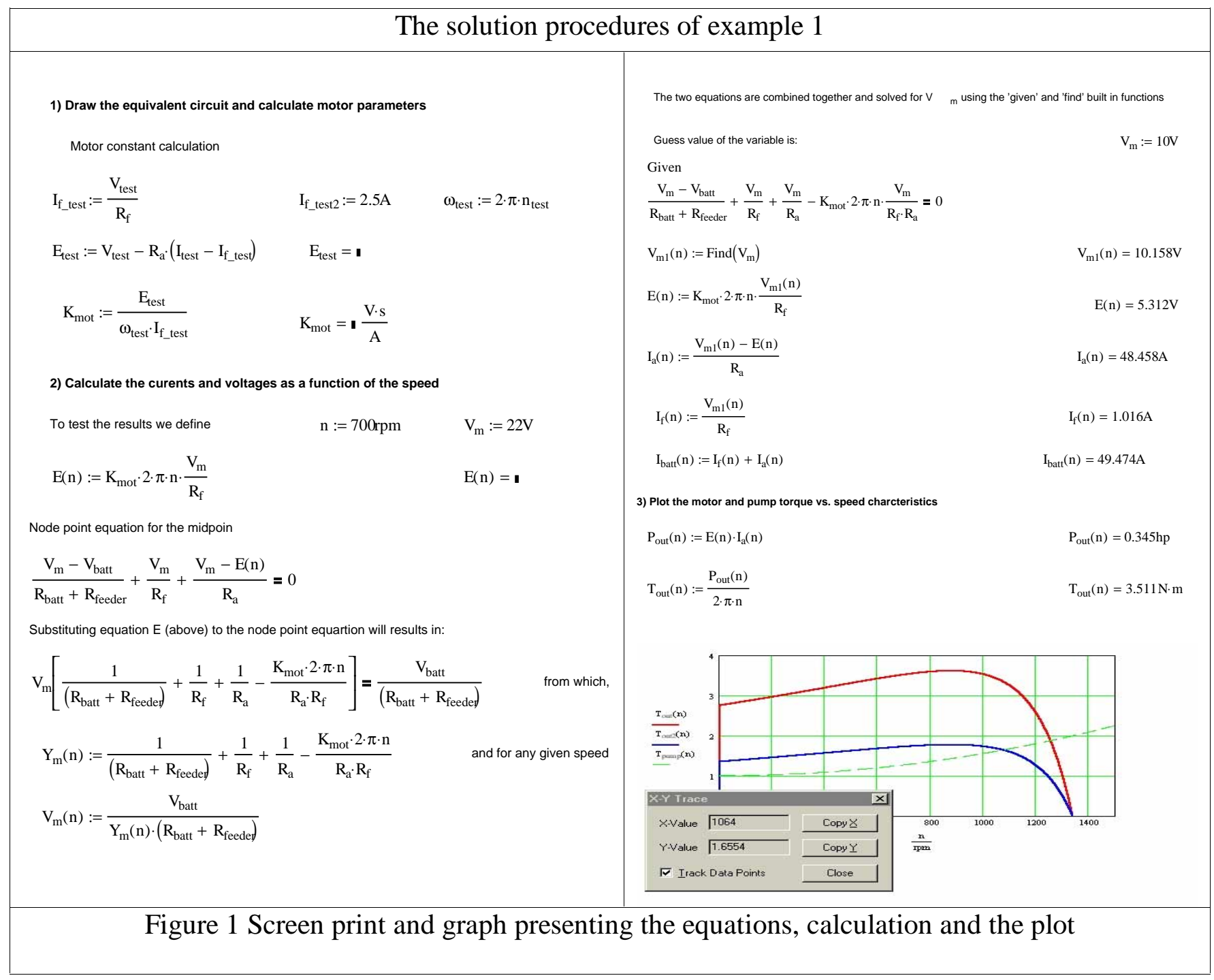

2.2 Application to solve power system equations

The example demonstrates the use of maximize and minimize functions to evaluate the maximum operating conditions of a distribution transformer. The professor guides the students to investigate the effect of parameter variations. Figure 2 shows a screen print out of the mathematical equation used and the results presented by graphs. The students conclude from this example the practicality of applying the built in functions to maximize the operations. Also how the transformer regulation is increased as the load increases. 


\section{Example 2}

The example shows a simple network analysis as shown. It is required to find the distribution transformer equivelant circuit and the regulation at different loading.

1- Data given are:

a- Supply equivalent Thevenin impedance

$\mathrm{X}_{\mathrm{net}}:=\frac{\frac{4600 \mathrm{~V}}{\sqrt{3}}}{2000 \mathrm{~A}} \cdot \mathrm{i} \quad \mathrm{X}_{\mathrm{net}}=1.328 \mathrm{i} \Omega$

b- Line impedance $\quad Z_{\text {line }}:=15 \mathrm{mi}(0.1+\mathrm{i} \cdot 0.6) \frac{\Omega}{\mathrm{mi}}$

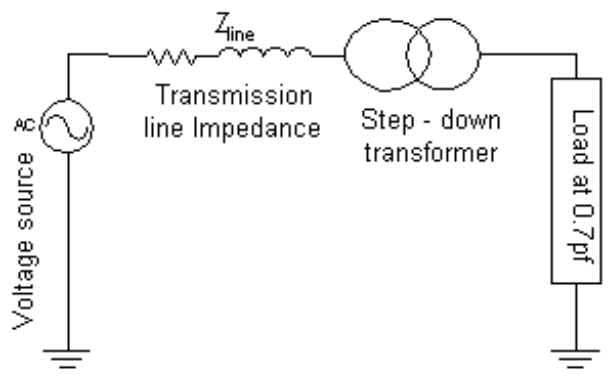

$\mathrm{Z}_{\text {line }}=1.5+9 \mathrm{i} \Omega$

The solution procedures for example 2

c- Transformer parameters - open and short circuit tests

c-1 Open circuit test at the low voltage side

$$
\begin{aligned}
& \mathrm{V}_{\mathrm{o} \_l n}:=\frac{\mathrm{V}_{\mathrm{o}}}{\sqrt{3}} \\
& \mathrm{P}_{\mathrm{o} \_1 \mathrm{f}}:=\frac{\mathrm{P}_{\mathrm{o}}}{3} \\
& \mathrm{R}_{\mathrm{m}}:=\frac{\mathrm{V}_{\mathrm{o} \_l n}{ }^{2}}{\mathrm{P}_{\mathrm{o} \_ \text {lf }}} \\
& \mathrm{R}_{\mathrm{m}}=96.182 \Omega \\
& \mathrm{X}_{\mathrm{m}}:=\frac{\mathrm{V}_{\mathrm{o} \_l n}{ }^{2}}{\mathrm{Q}_{\mathrm{o}}} \cdot \mathrm{i} \\
& \mathrm{X}_{\mathrm{m}}=10.273 \mathrm{i} \Omega
\end{aligned}
$$$$
\mathrm{V}_{\mathrm{o}}:=230 \mathrm{~V}
$$$$
\mathrm{I}_{\mathrm{o}}:=13 \mathrm{~A}
$$$$
\mathrm{P}_{\mathrm{o}}:=550 \mathrm{~W}
$$$$
\mathrm{S}_{\mathrm{o}}:=\mathrm{V}_{\mathrm{o} \_l n} \cdot \mathrm{I}_{\mathrm{o}}
$$$$
Q_{0}:=\sqrt{S_{o^{2}-P_{o_{-} l f}{ }^{2}}}
$$

c-2 Short Circuit tes

t High voltage side

$$
\mathrm{V}_{\mathrm{s}}:=160 \mathrm{~V}
$$

$$
\mathrm{I}_{\mathrm{s}}:=16 \mathrm{~A}
$$

$$
\begin{array}{ll}
\mathrm{V}_{\mathrm{s}_{-} \ln }:=\frac{\mathrm{V}_{\mathrm{s}}}{\sqrt{3}} & \mathrm{P}_{\mathrm{s}_{-} \text {lf }}:=\frac{\mathrm{P}_{\mathrm{s}}}{3} \\
\mathrm{X}_{\mathrm{S}}:=\mathrm{i} \cdot \sqrt{\mathrm{Z}_{\mathrm{s}}{ }^{2}-\mathrm{R}_{\mathrm{s}}{ }^{2}} & \mathrm{X}_{\mathrm{s}}=5.558 \mathrm{i} \quad \Omega
\end{array}
$$$$
\mathrm{Z}_{\mathrm{s}}:=\frac{\mathrm{V}_{\mathrm{s}_{\_} \mathrm{ln}}}{\mathrm{I}_{\mathrm{s}}}
$$$$
\mathrm{R}_{\mathrm{S}}:=\frac{\mathrm{P}_{\mathrm{s}_{-} \text {lf }}}{\mathrm{I}_{\mathrm{s}}{ }^{2}}
$$$$
\mathrm{R}_{\mathrm{s}}=1.563 \Omega
$$

2- Current as a function of the loa

d

$$
\mathrm{V}_{\text {load_ln }}:=\frac{230 \mathrm{~V}}{\sqrt{3}} \quad \mathrm{pf}_{\text {load }}:=0.7
$$

$\mathrm{I}_{\text {load }}\left(\mathrm{S}_{\text {load }}\right):=\frac{\mathrm{S}_{\text {load }}}{3 \cdot \mathrm{V}_{\text {load_ln }}} \mathrm{e}^{-\left(\mathrm{i} \cdot \operatorname{acos}\left(\mathrm{pf}_{\text {load }}\right)\right)}$

$$
\mathrm{I}_{\text {load }}(75 \mathrm{kV} \cdot \mathrm{A})=131.786-134.449 \mathrm{i} \quad \mathrm{A}
$$

2-a Magnetizing current

$$
\mathrm{I}_{\mathrm{m}}:=\frac{\mathrm{V}_{\text {load_ln }}}{\mathrm{X}_{\mathrm{m}}}+\frac{\mathrm{V}_{\text {load_ln }}}{\mathrm{R}_{\mathrm{m}}} \quad \mathrm{I}_{\mathrm{m}}=1.381-12.926 \mathrm{i} \quad \text { A }
$$

2-b Secondary current

$$
\mathrm{I}_{\mathrm{sec}}\left(\mathrm{S}_{\text {load }}\right):=\mathrm{I}_{\mathrm{m}}+\mathrm{I}_{\text {load }}\left(\mathrm{S}_{\text {load }}\right)
$$

2-c Primary current and voltage

$\mathrm{I}_{\text {prim }}\left(\mathrm{S}_{\text {load }}\right):=\frac{\mathrm{I}_{\text {sec }}\left(\mathrm{S}_{\text {load }}\right)}{\mathrm{a}}$

$$
\mathrm{a}:=\frac{4600}{230} \quad \mathrm{~V}_{\text {prim }}:=\mathrm{V}_{\text {load_ln }} \cdot \mathrm{a}
$$

3- Supply voltage

$$
\begin{aligned}
& \mathrm{V}_{\text {net }}\left(\mathrm{S}_{\text {load }}\right):=\mathrm{V}_{\text {prim }}+\mathrm{I}_{\text {prim }}\left(\mathrm{S}_{\text {load }}\right) \cdot\left(\mathrm{X}_{\text {net }}+\mathrm{Z}_{\text {line }}+\mathrm{R}_{\mathrm{s}}+\mathrm{X}_{\mathrm{s}}\right) \\
& \mathrm{V}_{\text {net }}(75 \mathrm{kV} \cdot \mathrm{A})=2.793+0.083 \mathrm{kV}
\end{aligned}
$$




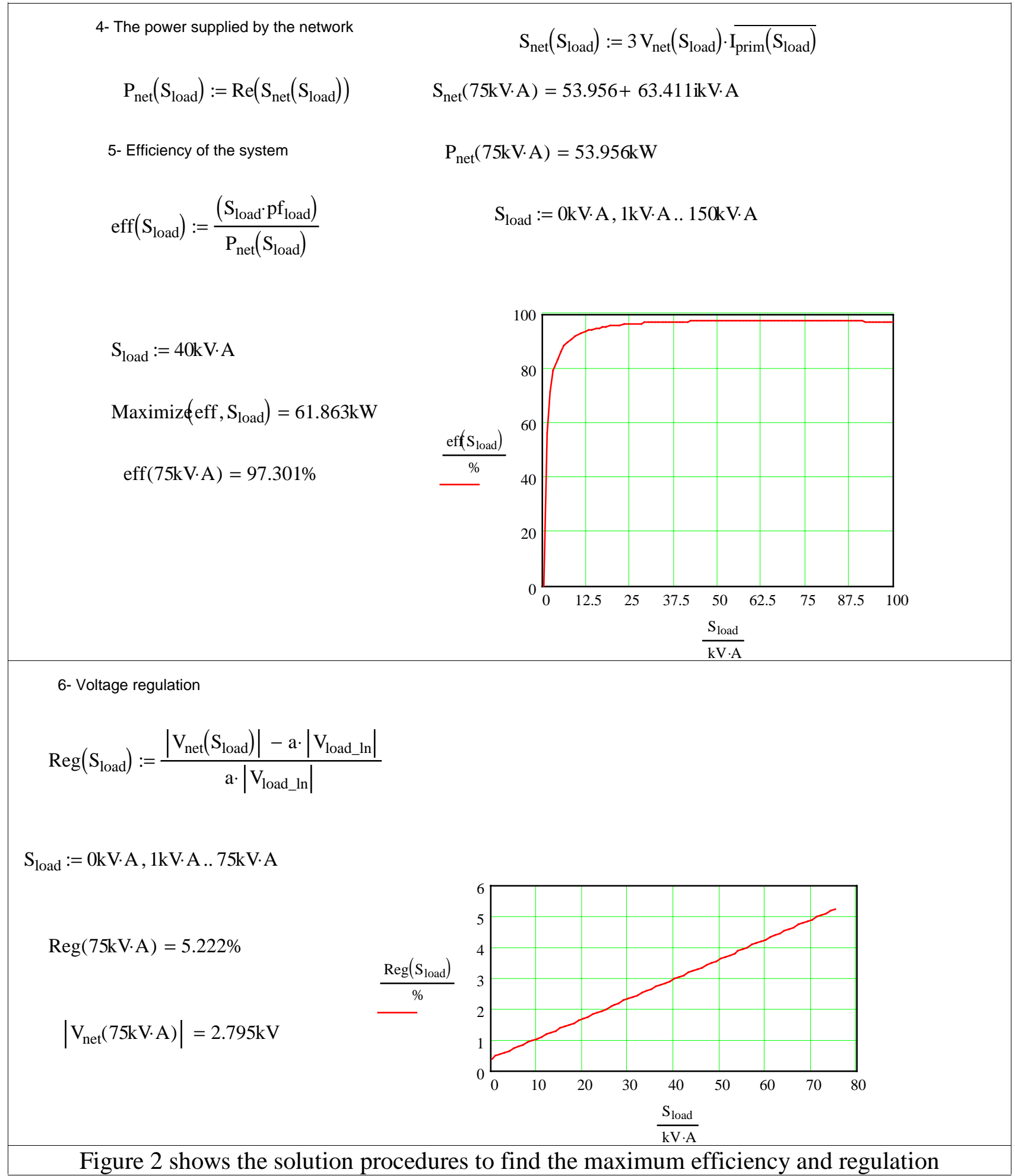

"Proceedings of the 2001 American Society for Engineering Education Annual Conference \& Exposition Copyright (02001, American Society for Engineering Education” 


\subsection{Application to solve power system stability equations}

The third example demonstrates the use of iteration routines (Given and Find, Maximize and Minimize functions) to evaluate the stability of a distribution system under no load and load. The professor guides the students to investigate the effect of parameter variations and study the stability of the system as the load value and its nature alters. Figure 3 shows a screen print out of the mathematical equation used and associated plots. The student concludes from this example the practicality of applying the built in functions to understand the system stability.

\section{Example 3}

A generator supplies a load and a network through a transformer. Determine the maximum power that can be transferred to the network, with and without the load.

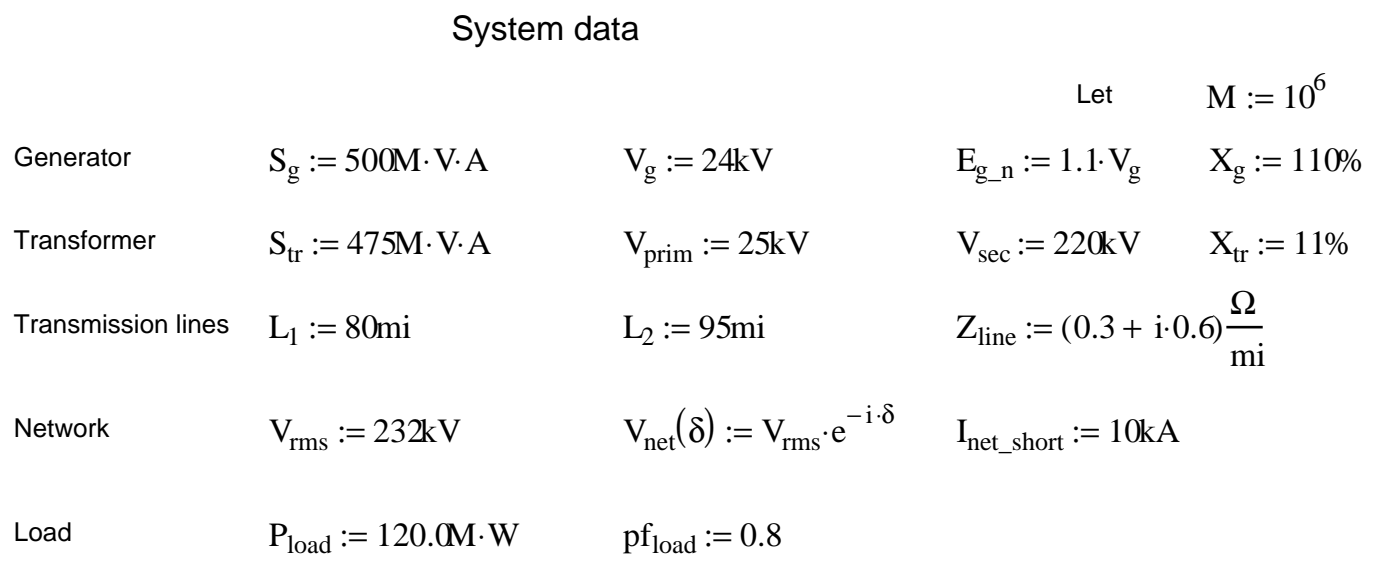

a- Example 3 line diagram of the distribution system.

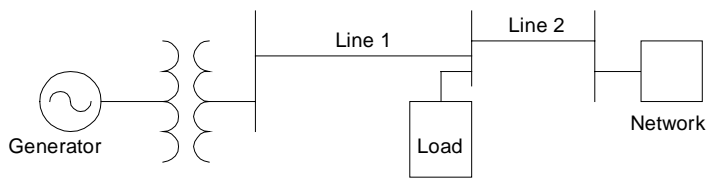

b- Equivalent circuit without load.

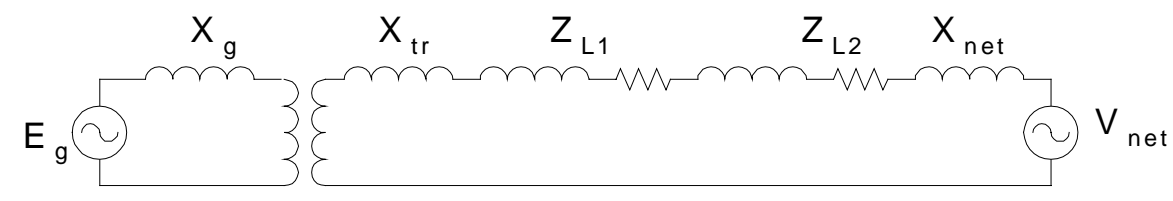

c- Equivalent circuit with load referred to the transformer primary.

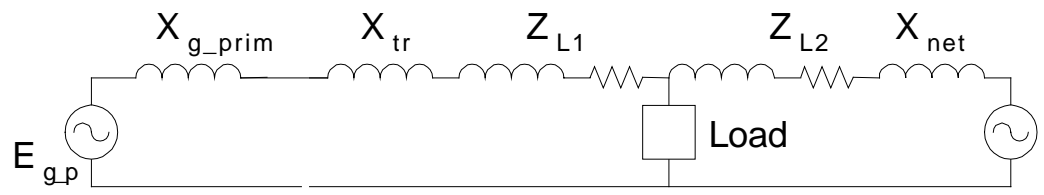




\section{The solution procedures for example 3}

1- Calculation of impedances and voltages

$\delta:=60 \mathrm{deg}$

$$
\begin{array}{llll}
\mathrm{X}_{\mathrm{g}}:=\mathrm{iX} \mathrm{X} \cdot \frac{\mathrm{V}_{\mathrm{g}}{ }^{2}}{\mathrm{~S}_{\mathrm{g}}} & \mathrm{X}_{\mathrm{g}}=1.267 \mathrm{i} \Omega & \mathrm{Z}_{\mathrm{L} 1}:=\mathrm{L}_{1} \cdot \mathrm{Z}_{\text {line }} & \mathrm{Z}_{\mathrm{L} 1}=24+48 \mathrm{i} \Omega \\
\mathrm{X}_{\mathrm{tr}}:=\mathrm{i} \cdot \mathrm{X}_{\mathrm{tr}} \cdot \frac{\mathrm{V}_{\mathrm{sec}}{ }^{2}}{\mathrm{~S}_{\mathrm{tr}}} & \mathrm{X}_{\mathrm{tr}}=11.208 \mathrm{i} \Omega & \mathrm{Z}_{\mathrm{L} 2}:=\mathrm{L}_{2} \cdot \mathrm{Z}_{\text {line }} & \mathrm{Z}_{\mathrm{L} 2}=28.5+57 \mathrm{i} \Omega \\
\mathrm{V}_{\text {net_n }}(\delta):=\frac{\mathrm{V}_{\text {net }}(\delta)}{\sqrt{3}} & \mathrm{X}_{\text {net }}:=\mathrm{i} \frac{\mathrm{V}_{\text {rms }}}{\sqrt{3} \cdot \mathrm{I}_{\text {net_short }}} & \mathrm{X}_{\text {net }}=13.395 \mathrm{i} \Omega
\end{array}
$$

2- The generaror excitation voltage and impedance is transfered to the primary

$$
\begin{aligned}
& \mathrm{a}:=\frac{\mathrm{V}_{\mathrm{prim}}}{\mathrm{V}_{\mathrm{sec}}} \quad \mathrm{a}=0.114 \quad \mathrm{E}_{\mathrm{g}_{-} \mathrm{p}}:=\frac{\mathrm{E}_{\mathrm{g}_{-} \mathrm{n}}}{\mathrm{a}} \quad \mathrm{E}_{\mathrm{g}_{\_} \mathrm{p}}=232.32 \mathrm{kV} \\
& \mathrm{X}_{\mathrm{g}_{-} \text {prim }}:=\frac{\mathrm{X}_{\mathrm{g}}}{\mathrm{a}^{2}} \quad \mathrm{X}_{\mathrm{g}_{\mathrm{P}} \text { prim }}=98.132 \mathrm{i} \Omega \quad\left|\mathrm{V}_{\text {net_n }}(\delta)\right|=133.945 \mathrm{kV} \\
& \text { 2.1 Load current } \quad \mathrm{V}_{\text {load_n }}:=\frac{220 \mathrm{kV}}{\sqrt{3}} \quad \mathrm{~V}_{\text {net_n }}(\delta)=66.973-116 \mathrm{ikV} \\
& \mathrm{I}_{\text {load }}\left(\mathrm{V}_{\text {load_n }}\right):=\frac{\mathrm{P}_{\text {load }}}{3 \cdot \mathrm{V}_{\text {load_n }} \cdot \mathrm{pf}_{\text {load }}} \cdot \mathrm{e}^{-\mathrm{i} \cdot \operatorname{acos}\left(\mathrm{pf} \mathrm{f}_{\text {load }}\right)} \quad \mathrm{I}_{\text {load }}\left(\mathrm{V}_{\text {load_n }}\right)=314.918-236.189 \text { iA }
\end{aligned}
$$

2.2 Power transfered to the network without load

$$
\begin{array}{ll}
\mathrm{I}_{\text {net }}(\delta):=\frac{\mathrm{E}_{\mathrm{g} \_\mathrm{p}}-\mathrm{V}_{\text {net_n }}(\delta)}{\mathrm{X}_{\mathrm{g} \_ \text {prim }}+\mathrm{X}_{\mathrm{tr}}+\mathrm{Z}_{\mathrm{L} 1}+\mathrm{Z}_{\mathrm{L} 2}+\mathrm{X}_{\text {net }}} & \mathrm{I}_{\text {net }}(\delta)=642.591-577.915 \mathrm{iA} \\
\mathrm{V}_{\mathrm{gen}}(\delta):=\mathrm{E}_{\mathrm{g} \_\mathrm{p}}-\mathrm{I}_{\text {net }}(\delta) \cdot \mathrm{X}_{\mathrm{g} \_ \text {prim }} & \left|\mathrm{V}_{\mathrm{gen}}(\delta) \cdot \sqrt{3} \cdot \mathrm{a}\right|=36.725 \mathrm{kV} \\
\mathrm{P}_{\text {net }}(\delta):=\operatorname{Re}\left(3 \overline{\mathrm{I}_{\text {net }}(\delta)} \cdot \mathrm{V}_{\text {net_n }}(\delta)\right) & \mathrm{P}_{\text {net }}(\delta)=330.222 \mathrm{M} \cdot \mathrm{W}
\end{array}
$$

2.3 The results

$\delta:=0 \operatorname{deg}, 1 \operatorname{deg} . .180 \mathrm{deg}$

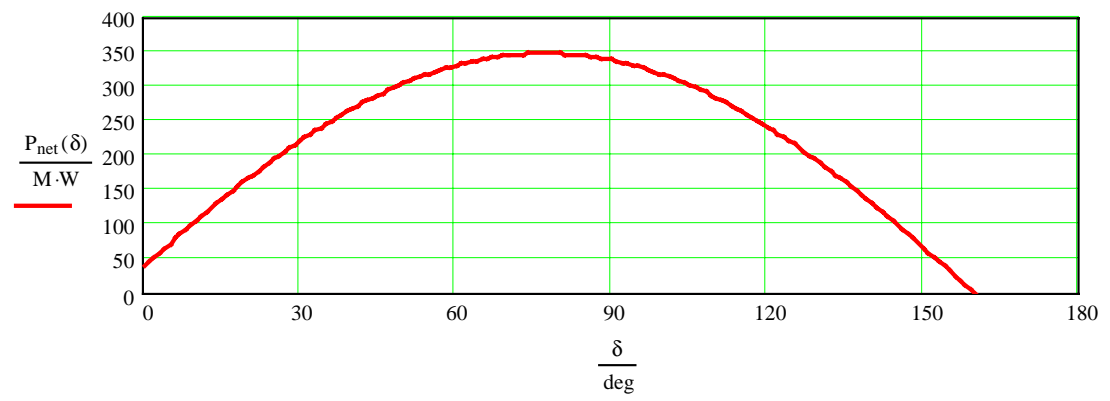

2.4 Find the maximum conditions

$\delta:=60 \mathrm{deg}$

$\operatorname{Maximiz}\left(\mathrm{P}_{\mathrm{net}}, \delta\right)=77.018 \mathrm{deg}$

$\left.\mathrm{P}_{\text {net }}\left(\operatorname{Maximiz} \notin \mathrm{P}_{\text {net }}, \delta\right)\right)=347.714 \mathrm{M} \cdot \mathrm{W}$

$$
\begin{aligned}
& \operatorname{Minimiz}\left(\mathrm{P}_{\text {net }}, \delta\right)=-102.982 \mathrm{deg} \\
& \mathrm{P}_{\text {net }}\left(\operatorname{Minimize}\left(\mathrm{P}_{\text {net }}, \delta\right)\right)=-451.185 \mathrm{M} \cdot \mathrm{W}
\end{aligned}
$$

"Proceedings of the 2001 American Society for Engineering Education Annual Conference \& Exposition Copyright C2001, American Society for Engineering Education" 
3- Power transfered to the network with load

3.1 Calculation of the load voltage

Let $\quad$ Tol $:=0.001$

Given

$$
\begin{array}{ll}
\frac{E_{\mathrm{g}_{-} \mathrm{p}}-\mathrm{V}_{\text {load_n }}}{\mathrm{Z}_{\mathrm{L} 1}+\mathrm{X}_{\mathrm{g} \_ \text {prim }}+\mathrm{X}_{\text {tr }}}-\left(\frac{\mathrm{P}_{\text {load }}}{3 \cdot \mathrm{V}_{\text {load_n }} \cdot \mathrm{pf}_{\text {load }}} \cdot \mathrm{e}^{-\mathrm{i} \cdot \mathrm{acos}(\mathrm{pf} \text { load }}\right) & +\frac{\mathrm{V}_{\text {net_n }}(\delta)-\mathrm{V}_{\text {load_n }}}{\mathrm{Z}_{\mathrm{L} 2}+\mathrm{X}_{\text {net }}}=0 \\
\mathrm{~V}_{\text {load_nut }}(\delta):=\operatorname{Find}\left(\mathrm{V}_{\text {load_n }}\right) & \mathrm{V}_{\text {load_nut }}(\delta)=121.929-102.931 \mathrm{kVV}
\end{array}
$$

3.2 Network current and power absorbed

$$
\begin{array}{ll}
\mathrm{I}_{\text {net_nut }}(\delta):=\frac{\mathrm{V}_{\text {net_n }}(\delta)-\mathrm{V}_{\text {load_nut }}(\delta)}{\mathrm{Z}_{\mathrm{L} 2}+\mathrm{X}_{\text {net }}} & \mathrm{I}_{\text {net_nut }}(\delta)=-0.431+0.606 \mathrm{ikA} \\
\mathrm{P}_{\text {net_nut }}(\delta):=\operatorname{Re}\left(3 \cdot \mathrm{V}_{\text {net_n }}(\delta) \cdot \overline{\mathrm{I}_{\text {net_nut }}(\delta)}\right) & \mathrm{P}_{\text {net_nut }}(\delta)=-297.558 \mathrm{M} \cdot \mathrm{W}
\end{array}
$$

\section{$\delta:=0 \operatorname{deg}, 5 \operatorname{deg} . .180 \mathrm{deg}$}

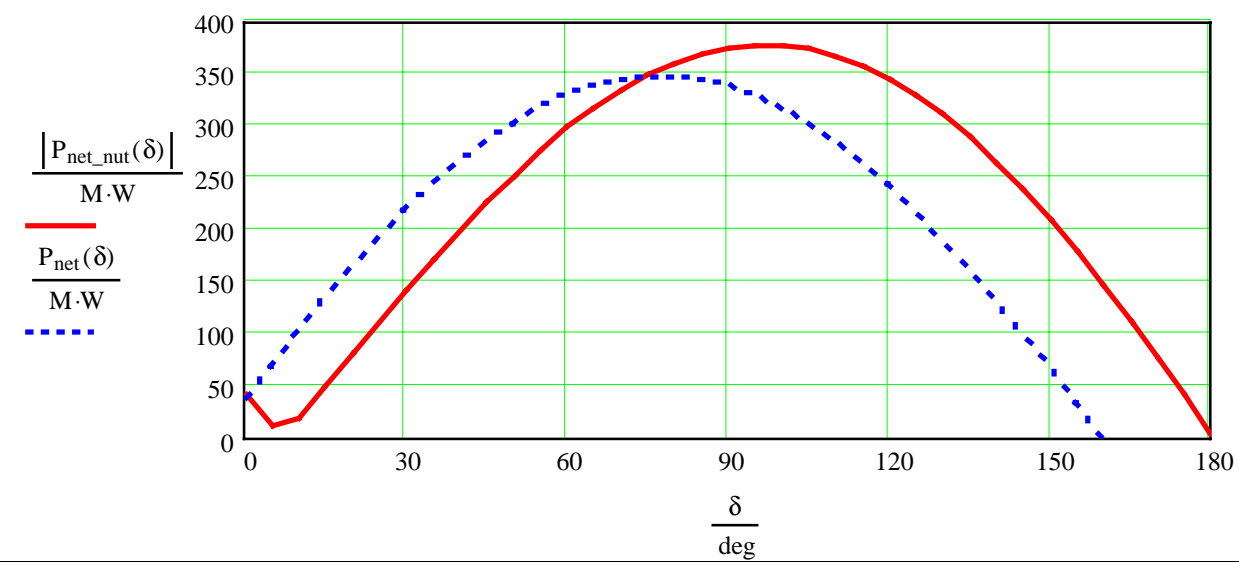

In the above cases, the students performed all of the calculations (observations and description) within the class hour. Thus, enhancing their understanding of the course material while simulating the problem. By manipulating the external affecting variables and the use of theory (prediction and interaction) near practical cases are tested. This is an advantage over the textbook examples, which limit the equation output result to one point setting of the internal or external variables.

\section{Conclusion}

MathCad software has a high potential for the analysis of much engineering system performance and can be used in simulation techniques effectively. The use of the built in functions of the software in an interactive and easy way to generate the complete characteristics over the entire possible range rather than one operating point is more informative for the student. "Proceedings of the 2001 American Society for Engineering Education Annual Conference \& Exposition 
This is one of the advantages over the numerical examples normally presented in the textbook. As computing languages are not essential, the undergraduate engineer can investigate different study cases and widen their problem solving abilities. The presented method has been tested in the last four years at Arizona State University to teach the junior level "energy conversion and transfer" course. Student's interest increased significantly since the introduction of the interactive problem solving in a computer equipped classroom.

\section{References}

1- Yamayee, Z.A. and Bala, J. L. " Electromechanical Energy Devices and Power Systems". John Wiley \& Sons publication, 1994 edition.

2- Harger, R. O. "Learning in a computer classroom with an Interactive Book", FIE'96 Proceedings, PP (1413-1415).

3- Agelidis, V.G. "Incorporating Software Tools in Electrical Engineering Laboratory Experiments - AN Example". IEEE Multimedia Engineering Education, PP (319-328).

4- Nehrir, M. H. Fatehi, F. and Gerez, V. "Computer Modeling for Enhancing Instructions of Electric Machinery”. IEEE Transactions On Education, Vol. 38, No.2, May 1995, PP(166170).

5- Lightner, M. Avery, J. “ A paperless circuits laboratory: vison and reality”. FIE'96 proceedings, PP(1186-1190).

6- Veglis, A. Barbargires, C.A, and Pombortsis, A. " An interactive laboratory exercise for teaching computer science students network performance evaluation using MathCad and Mathconnex". 29 $9^{\text {th }}$ ASEE, IEEE frontiers in Education conference. November 10-13, 1999. $\mathrm{PP}(13 b 3-16)$.

\section{Biography}

Gorge Karady was born in Budapest, Hungary. He received his BSEE and Doctor of Engineering degree from the Technical University of Budapest in 1952 and 1960, respectively. Dr. Karady was appointed to Salt River Project Chair professor at Arizona State University in 1986, where he is responsible for the electrical power education and performs research in power electronics, high voltage techniques and electrical power. Dr. Karady is a registered professional engineer in New York, New Jersey and Quebec. He is the author of more than 100 technical papers. Presently he is the chairman of IEEE subcommittee on lighting and insulators.

Khalid A. Nigim was born in Gaza in 1955. He graduated with a Bachelor of Science degree in Electrical Engineering from the University of Zagazig, Cairo, Egypt, in 1979. Subsequently, he obtained the Doctorate in Engineering at the University of Leicester, Leicester, UK, in 1983. He has been an Assistant Professor of Electrical Engineering at Birzeit University, West Bank, where he was responsible for the electrical machine, energy conversion and power electronics courses and performs research in power electronics subjects relating induction machine speed control and power conditioning systems. Currently he is a visiting fellow at Arizona State University, Power engineering research center for the year 2001. Dr. Nigim is an IEEE senior member.

"Proceedings of the 2001 American Society for Engineering Education Annual Conference \& Exposition Copyright C2001, American Society for Engineering Education” 